\title{
Maternidade: uma forma de opressão?
}

\author{
Carolina Bernardini Antoniazzi ${ }^{1}$
}

Resumo: O presente artigo persegue a seguinte questão: seria a maternidade uma forma de opressão? Para tanto, partimos do conceito de opressão formulado por bell hooks. A fim de analisar a experiência da maternidade enquanto vivida por um sujeito único, mas, ao mesmo tempo, constrangida por estruturas sociais generificadas, ancoraremos a maior parte de nossa análise em Iris Young. O pensamento da autora é habilidoso ao entrelaçar uma corrente fenomenológica à crítica social, dando conta de problemas que surgem nas pautas feministas acerca de subjetividades em relação a marcadores sociais. É pertinente, ainda, na medida em que Young se ocupa amplamente de temas e problemas ligados à maternidade, dando maior ênfase a este debate do que normalmente observamos. Silvia Federici também é central neste ponto, fornecendo ferramentas para entendermos a reprodução como um trabalho. Procuramos demonstrar como as tarefas do cuidado estão amplamente relacionadas à maternidade e, provavelmente, foram naturalizadas como pertencentes à esfera feminina em decorrência do próprio trabalho reprodutivo.

Palavras-chave: Iris Young - Gênero - Cuidado - Trabalho reprodutivo - Opressão

\section{Motherhood: A Form of Oppression?}

\begin{abstract}
This article addresses the following question: would motherhood be a form of oppression? For that, we start from the concept of oppression formulated by bell hooks. In order to analyze the experience of motherhood as lived by a single subject, but, at the same time, constrained by gendered social structures, we will anchor most of our analysis in Iris Young. The author's thinking is skillful in interweaving a phenomenological approach with social criticism, addressing problems that arise in feminist agendas about subjectivities in relation to social markers. It is also relevant, as Young is largely concerned with issues and problems related to motherhood, giving greater emphasis to this debate than we normally observe. Silvia Federici is also central at this point, providing tools to understand reproduction as a work. We tried to demonstrate how the tasks of care are largely related to motherhood and, probably, were naturalized as belonging from the female sphere as a result of the reproductive work itself.
\end{abstract}

Keywords: Iris Young - Gender - Care - Reproductive work - Oppression

\footnotetext{
${ }^{1}$ Pesquisadora de mestrado pelo Departamento de Filosofia da USP, Orientadora: Silvana de Souza Ramos. Bolsista CAPES. E-mail: carolina.antoniazzi@usp.br
} 


\section{Introdução}

"Ser oprimida significa ausência de opções.", afirma bell hooks² em Mulheres negras: moldando a teoria feminista. Partimos deste conceito de opressão presente neste ensaio. Explico: bell hooks nos empresta seu olhar para entendermos como podemos - e devemos — levar em consideração a perspectiva única das mulheres negras. Como essas mulheres não encontram o "Outro" a quem possam oprimir, pois, normalmente, concentram todos os marcadores (raça, classe e sexo) dos que estão à margem, podem desempenhar na construção da teoria feminista um enriquecimento para uma ideologia libertadora. Isto se articula ao enunciado destacado na medida em que, segundo bell hooks, devemos olhar para a opressão ${ }^{3}$ com cautela, a fim de não a confundir com a exploração e discriminação a que muitos grupos estão submetidos, mas que ainda podem, de algum modo, oprimir outros. Devemos observar, ademais, que a opressão pode sim estar presente em determinados contextos, desde que seja feito o recorte específico para tanto. Isto posto, nosso intuito é perseguir a seguinte pergunta: seria a maternidade uma forma de opressão?

O texto de bell hooks dialoga diretamente com a obra $A$ mistica feminina de Betty Friedan que, segundo ela, abriu caminho para o feminismo contemporâneo. bell hooks é direta ao afirmar que o problema de um grupo seleto de mulheres dos Estados Unidos brancas casadas, classe média e alta, com formação universitária — foi posto como querendo ser comum a todas as mulheres dos Estados Unidos. Suas reivindicações pediam pelo fim do trabalho doméstico e uma inserção no mercado de trabalho - quando se sabe que mais de um terço já participava da força de trabalho. Note-se que bell hooks não busca dessa forma deslegitimar as reivindicações de feministas brancas, apenas apontar que eram extremamente particulares quando queriam ser universais. Mais, estas se revelam muitas vezes racistas, classistas e sexistas (por pressupor a heterossexualidade compulsória) quando expostas a demandas que não fazem parte da pauta do feminismo branco.

O que nos salta aos olhos em bell hooks é que, caso desejemos pensar em questões ligadas ao feminismo de modo que não operemos, nós mesmas, opressões racistas e classistas, devemos atentar-nos sempre à interseccionalidade, afirmando-a. De tal maneira que, ao desenvolver uma teoria crítica acerca de experiências de indivíduos situados, faz-se relevante notar que a experiência de quem escreve também é, em si, situada, e portanto, limitada e circunscrita a um determinado ponto de vista. Sendo cada perspectiva única, o que se pode fazer é uma descrição que engloba experiências diversas; que não fale por elas, mas, sim, com elas.

Isto posto, e tendo por premissa o conceito de opressão como ausência de opção de bell hooks, perseguiremos nosso caminho analítico através do pensamento de Iris Young, especialmente, sob o recorte de gênero ${ }^{4}$. Nos interessa a leitura de Young, uma vez que a autora consegue articular uma crítica social sem abrir mão da subjetividade dos indivíduos. Isto porque, ao refletir sobre experiências corporais de sujeitos, utilizando-se de conceitos

\footnotetext{
${ }^{2}$ A grafia em letras minúsculas é uma escolha da própria autora, que pretende dar destaque ao conteúdo de sua escrita e não à sua pessoa.

${ }^{3}$ É importante salientar que bell hooks entende o uso da palavra opressão também como forma de resistência política e estratégia para politização da luta feminista.

${ }^{4}$ Caso os outros marcadores fossem tomados como pontos de articulação principais, faríamos outras conexões e daríamos maior centralidade e peso a outros debates.
} 
como corpo vivido e experiência encarnada, derivados da fenomenologia, pode assegurar o âmbito da individualidade. Ao mesmo tempo, seus ensaios engajam-se em críticas sociais, mostrando como esses mesmos corpos são constrangidos por normas sociais que regulam seus comportamentos e ações no mundo. A articulação entre uma corrente fenomenológica que pensa a subjetividade - e uma corrente social - que problematiza politicamente esses corpos - constitui a chave do entendimento do pensamento de Young.

\section{Por que gênero?}

De início, faz-se pertinente justificar o recorte de gênero. Não pretendemos traçar e retomar o debate acerca do conceito de gênero, ou nos aprofundar nele mesmo. Assumimos que gênero trata de uma categoria social, querendo opor-se a ideia de sexo biológico (que seria um dado da natureza). Isto significa que um indivíduo pode nascer com determinado órgão sexual, sem que se identifique com ele. O gênero seria passível de mudança, portanto. Ao gênero também seria possível atribuir uma construção social e cultural, sobre identidades. Como nos interessa analisar uma opressão social, que recai sobre aqueles indivíduos que portam signos do feminino, o recorte de gênero se faz mais interessante do que o de raça ou classe, como pretendemos demonstrar adiante.

Como dissemos, devemos estar atentas à interseccionalidade. Sua importância tornase exemplar quando Angela Davis aponta como a esterilização forçada de mulheres (principalmente as indígenas, mexicanas, porto-riquenhas e negras) nos Estados Unidos com um viés claramente racista - muda o tom do debate em relação ao aborto. Não obstante as mulheres de baixa renda serem aquelas mais expostas aos riscos de uma interrupção de gravidez de forma clandestina e ilegal, o que, por muitas vezes, pode levá-las a morte, as mulheres negras, desde os tempos escravistas, utilizavam-se de técnicas para a interrupção forçada da gravidez. Assim, ter direito e autonomia sobre seus corpos é pauta imprescindível de luta. Contudo, levando em consideração que o Estado promoveu um controle forçado de natalidade da população negra (mas não só), a possibilidade de reprodução dessas mulheres é uma afirmação de sua raça enquanto aquela que vem sendo oprimida há séculos. De tal forma que mulheres negras e mulheres brancas encaram a questão do aborto de perspectivas e experiências distintas.

A esterilização forçada é uma prática existente até os dias atuais ${ }^{5}$, como forma de controle populacional realizado pelo Estado, normalmente em populações de baixa renda e raças não brancas. Observe-se que o controle reprodutivo por parte do Estado é um controle dos corpos, e que se fez presente, pelo menos, desde o surgimento do regime capitalista, como aponta Silvia Federici. Em o Calibã e a Bruxa, a autora sustenta que os métodos disciplinares adotados pelo Estado para regular a procriação e quebrar o controle das mulheres sobre a reprodução é associada à crise demográfica. À ideia de que a riqueza de uma nação e sua prosperidade estava atrelada ao seu crescimento populacional, somou-se a necessidade capitalista de exploração de mão de obra. As mulheres foram alienadas de seus corpos na medida em que eram escravizadas à procriação.

\footnotetext{
${ }^{5}$ Uma simples busca na internet sobre "esterilização forçada" fornece matérias recentes sobre o assunto.
} 
Enquanto na Idade Média elas podiam usar métodos contraceptivos e haviam exercido um controle indiscutível sobre o parto, a partir de agora seus úteros se transformaram em território político, controlados pelos homens e pelo Estado: a procriação foi colocada diretamente a serviço da acumulação capitalista. ${ }^{6}$

Este seria, inclusive, o primeiro aspecto da acumulação primitiva de capital, que Marx não teria reconhecido. A geração da mão de obra em si mesma poderia ter sido encarada como um terreno de exploração, logo, de possível resistência. Mas a procriação sempre foi tida como "natural" enquanto colocada à serviço da acumulação capitalista. Já aqui observamos o cruzamento dos marcadores de gênero, raça e classe, tendo em vista que as camadas mais baixas da sociedade são as mais vulneráveis e alvo das ações estatais.

Federici nos mostra como a caça às bruxas relaciona-se com o surgimento do capitalismo e de que forma às mulheres foi imposto o trabalho reprodutivo. Levando em conta que tal trabalho cabe às mulheres, ela analisa a opressão desse grupo. A questão que perseguimos, contudo, tenta não restringir nosso objeto de estudo: o corpo gestante parece não se ater ao gênero, uma vez que há a possibilidade de pessoas transexuais gerarem uma criança. Não há, inclusive, a pressuposição de um relacionamento heterossexual para a criação de um filho. Mas, por outro lado, ainda são as mulheres aquelas que mais carregam uma gestação e aquelas que exercem majoritariamente as práticas do cuidado. O primeiro fato pode apoiar-se na biologia, mas, o segundo, deve-se verificar a partir de uma construção social. Assim, como nos mostrou Simone de Beauvoir, biologia não é destino. Logo, a análise da maternidade enquanto função social é mais pertinente se tomada pelo recorte de gênero que, justamente, pressupõe este debate. Em outras palavras, a gestação e a maternidade possuem diferentes consequências caso as analisemos sob outros marcadores, como de raça ou classe, como indicamos a partir de Angela Davis. Mas, justamente pelo trabalho reprodutivo recair sobre as mulheres, escolhemos o recorte de gênero: ter o corpo biológico de uma mulher não deveria ter por consequência o fato de caber às mulheres o trabalho reprodutivo e as práticas do cuidado ${ }^{7}$.

\section{Iris Young e a experiência da maternidade}

Segundo indicamos, nosso intuito é entender em que medida pode haver opressão na experiência da maternidade. Como tal experiência não é abstrata, mas, sim, localizada em um corpo específico, situado, é necessário que antes de adentrarmos no âmbito social propriamente, façamos uma primeira análise desse corpo gestante enquanto corpo próprio. Iris Young retoma o conceito de corpo próprio da fenomenologia de Simone de Beauvoir, segundo proposta de Toril Moi em O que é uma mulher?, a fim de teorizar as subjetividades,

\footnotetext{
${ }^{6}$ FEDERICI, Calibã e a Bruxa: Mulheres, Corpo e Acumulação Primitiva, p. 178.

${ }^{7}$ É importante salientar que observando o critério de classe, por exemplo, as tarefas do cuidado podem ser lidas de maneiras distintas se tomadas em relação às mulheres de classe alta e classe baixa. Isto porque, apesar da pressão social que as mulheres de classe alta possam sofrer acerca da responsabilização por tais tarefas, na maioria das vezes, têm condições de delegá-las. Ocorre que essa delegação será feita, quase sempre, para outra mulher, de classe mais baixa. O que pode ser verificado também em relação ao trabalho doméstico. É também por esse motivo que demos ênfase ao recorte de gênero. Cf. MISSAGGIA, "Ética do cuidado: duas formulações e suas objeções".
} 
sem o perigo de se cair em um reducionismo biológico ou um essencialismo de gênero. Do mesmo modo que bell hooks aponta para o perigo de uma teoria feminista que pretenda libertar as mulheres sem se questionar quem seriam essas mulheres e do que libertá-las, Toril Moi revisita a teoria de Simone de Beauvoir para refundar a teoria feminista não mais no par sexo/gênero, mas, sim, no conceito de corpo próprio. O corpo vivido seria uma ideia unificada de um corpo próprio agindo e experienciando um contexto sociocultural específico; seria um corpo-em-situação. Propor a utilização do conceito de corpo vivido, em vez de gênero, para a teorização da subjetividade seria sugerir que cada corpo próprio possui sua especificidade, sem que seja constrangido por seu sexo biológico a agir e a se expressar de determinada maneira, pois cada corpo seria uma singularidade a partir do qual vive a facticidade e poderia desenhar sua liberdade.

Esta questão insere-se na problemática do par sexo/gênero, o qual buscou abrir um primeiro horizonte de possibilidades às mulheres. O sexo enquanto dado biológico não poderia ser o fundamento da inferioridade da mulher, restando entender o que colocaria a mulher no lugar de Outro. Para tanto, surge a ideia de gênero como referência para a constituição das subjetividades no âmbito social e suas interações. Tal diferenciação alargou o campo de opção às mulheres, distanciando seus comportamentos, temperamentos e conquistas do âmbito do biológico ou das explicações naturais. Assim, era possível afirmar que homens e mulheres são diferentes no que tange a sua biologia e papel reprodutivo relativo ao sexo - , porém tais diferenças não fundamentam as desigualdades sofridas no campo social — relativo ao gênero —, o qual é construído e passível de mudança, portanto.

O que passa a ser questionado em seguida é o próprio conceito de gênero. Sem nos alongar sobre questão específica, o conceito de gênero seria problemático na medida em que não seria capaz de abarcar a multiplicidade de singularidades possíveis, criando seus próprios excluídos, visto não se enquadrarem nessa norma ${ }^{8}$. Segundo leitura de Moi, o conceito de gênero deveria ser substituído, portanto, pelo conceito de corpo vivido. Young concorda que o conceito de gênero seja problemático para teorizar subjetividades, mas não abre mão dele, tendo em vista que há estruturas sociais que incidem diretamente na liberdade e bem-estar de indivíduos. A teoria feminista deve ser capaz de se engajar em projetos de críticas sociais e políticas, de modo que identifique injustiças dentro de certas instituições e relações sociais para propor ações de mudanças. Segundo Young:

Nós precisamos de ferramentas para entender como e por que certos padrões na alocação de tarefas ou reconhecimento de status persistem de maneiras que limitam as opções de muitas mulheres e da maioria das pessoas cujas escolhas sexuais se desviam da heteronormatividade. Uma importante mudança conceitual ocorre, no entanto, quando entendemos o conceito de gênero como uma ferramenta para teorizar mais as estruturas do que os sujeitos. ${ }^{9}$

Entendendo o conceito de gênero, portanto, como uma ferramenta para teorizar estruturas e entender como relações de opressão se dão de modo generificado na sociedade,

\footnotetext{
${ }^{8}$ Judith Butler é central neste debate, cf. BUTLER, Problemas de Gênero.

${ }^{9}$ YOUNG, On female body experience: "Throwing like a girl" and other essays, p. 21. Todas as citações de Iris Young são de tradução minha. Daqui em diante, sem menção.
} 
podemos pensar a maternidade sob este recorte de gênero. Já que, enquanto o corpo equipado com útero e ovários é ainda o único capaz de realizar o trabalho reprodutivo, convém questionar o porquê se segue que todas as obrigações advindas deste processo, recaiam sobre estas pessoas. Convém questionar, também, este fato ser tomado como "natural", quando, na realidade, é um trabalho não remunerado que desencadeia uma série de implicações.

Compreendemos as estruturas sociais divididas em três eixos básicos: divisão sexual do trabalho, tendo por base a separação da esfera público e privada, normas da sexualidade que privilegiam as relações heterossexuais, e hierarquias de poder baseadas no gênero, ou seja, privilégio dos valores ligados ao masculino. As estruturas posicionam indivíduos em relações de trabalho e produção, poder e subordinação, desejo e sexualidade, prestígio e status. Desse modo, a análise de um relato estrutural oferece uma maneira de entender a desigualdade de oportunidades, opressão e dominação. Para explicar e descrever algumas estruturas e processos que engendram diferentes oportunidades e privilégios na sociedade contemporânea, é preciso apelar ainda para o conceito de gênero. O gênero é melhor entendido como uma forma particular de posicionamento social dos corpos vividos em diferentes relações, seja pessoal, seja dentro de instituições e de processos sociais, historicamente localizados, e que têm efeitos concretos sobre o ambiente no qual as pessoas agem e reproduzem relações de poder e de privilégio. Um mesmo indivíduo pode ocupar múltiplas posições dentro de diferentes estruturas — é por isso que bell hooks pode dizer que grupos que ocupam posições de opressão por um lado, podem ser opressores por outro. Como são exemplos os homens negros e as mulheres brancas. Nas palavras da autora:

Os homens negros podem ser vitimados pelo racismo, mas o sexismo lhes permite atuar como exploradores e opressores das mulheres. As mulheres brancas podem ser vitimizadas pelo sexismo, mas o racismo lhes permite atuar como exploradoras e opressoras de pessoas negras. ${ }^{10}$

A divisão sexual do trabalho pauta as divisões de trabalho nas sociedades modernas, dividindo-se em público e privado. À esfera privada, normalmente associada ao trabalho doméstico e de dentro de casa, comporta as tarefas do cuidado em sentido amplo — dos corpos, das necessidades básicas, das questões emocionais e primárias de qualquer pessoa além do cuidado específico com crianças e idosos. Este trabalho, apesar de ser a base de formação de todo e qualquer indivíduo, bem como tarefa imprescindível e invisibilizada, não é remunerado. Diversas autoras feministas ${ }^{11}$ já apontaram o trabalho doméstico e as práticas do cuidado como aquelas que sustentam o regime capitalista. Sem esse trabalho essencial e invisibilizado, as outras relações de trabalho, aquelas da esfera pública, não aconteceriam. Além do caráter material, esta tarefa é perpassada por um caráter intangível das relações pessoais. Há certo tipo de energia vital e poder despendidos pelas mulheres em relação aos homens, a fim de liberar estes para trabalhos mais essenciais e criativos ${ }^{12}$. Essa característica do cuidado emocional, normalmente ligada ao feminino, escamoteia-se no chamado amor de mãe, que nutre emocionalmente seus filhos, para que os meninos tornem-se intelectuais independentes e as meninas outras mães.

\footnotetext{
10 hooks, Mulheres negras: moldando a teoria feminista, pp. 207-208.

${ }^{11}$ Gayle Rubin, Iris Young, Angela Davis, Susan Okin, Virginia Wolf, Silvia Federici, dentre outras.

${ }^{12}$ YOUNG, Justice and the Politics of Difference, p. 51.
} 
Em Vozes que se Cruzam, Young analisa de maneira mais aprofundada (principalmente nos capítulos de IV a VI) de que modo se estabelece, quais são as consequências, e propõe algumas soluções, para a divisão sexual do trabalho ${ }^{13}$. A base central para a crítica de Young encontra-se na ideia de que os indivíduos devem ser independentes. Essa independência pode ser lida em dois sentidos (que muitas vezes se implicam): independência econômica, como autossuficiência para manter-se economicamente sem necessitar de ajuda ou contribuição externa, recorrentemente lido como um emprego estável e bem pago; e, independência como autonomia, em que escolhas sobre ações a serem tomadas não dependam de outrem ou não precisem obedecer a ordem de outrem. A lógica neoliberal postula que um cidadão configura-se como aquele indivíduo que contribui para a sociedade e é capaz de manter-se sozinho economicamente, encerrando-se em sua individualidade. De modo muito simplificado, esse ideário dá base aos desdobramentos estruturais e políticos que regem as relações sociais. Em primeiro lugar, porque pressupõe um homem branco, adulto, economicamente estável e detentor de propriedades. Em segundo lugar, porque não considera que este mesmo homem em, pelo menos, dois momentos de sua vida também será dependente de alguém - quando criança e idoso. $\mathrm{O}$ argumento principal aqui é que todo indivíduo, em algum momento da vida, será dependente de outra pessoa. E, quem se encarregará desse cuidado, serão as mulheres ${ }^{14}$.

Assumir primeiramente a dependência como valor comum a todos os cidadãos, uns mais, outros menos, já nos pouparia de uma série de consequências indesejáveis. Reconhecer, portanto, que a prática do cuidado é um trabalho e deve ser dividido socialmente sem estruturas de gênero, seria um primeiro remédio. Mas, tendo em conta que essa divisão sexual do trabalho mantém as mulheres na esfera privada — não remunerada e invisível — e tornaas já de início dependentes (ou de um outro particular ou do Estado). Mesmo quando conseguem estar na esfera pública, ocupam, em geral, os lugares também do cuidado (como enfermeiras, professoras de educação infantil, cuidadoras, etc.) e, quando não, acumulam funções/jornadas de trabalho estando, portanto, muito mais sobrecarregadas. Para além disso, ocupam poucos cargos de liderança e, quando o fazem, esbarram nas hierarquias de poder baseadas no gênero - serão mais questionadas, tidas menos em conta, receberão menores salários que seus pares do sexo masculino. Todos esses pontos geram um sistema que se retroalimenta, fazendo com que a divisão sexual seja reforçada.

Uma divisão sexual do trabalho é, portanto, apropriada e compatível entre mulheres não cidadãs emocionalmente apegadas a homens e crianças cuja

\footnotetext{
13 É importante ressaltar que Iris Young analisa casos estadunidenses, mas como se volta à análise de uma sociedade capitalista e com estruturas neoliberais de poder, é possível expandir e aplicar sua lógica a outras sociedades contemporâneas que apresentam estruturas similares.

${ }^{14}$ A autora não se pergunta propriamente de onde advém essa naturalização da prática do cuidado assumido pelas mulheres e, ouso arriscar neste momento, que isto se deve, justamente, à maternidade. Isto porque, sendo a reprodução um trabalho tido como "natural", há um primeiro pré conceito de que as mulheres seriam seres mais propensos aos cuidados por conta dessa sua pretensa natureza (a procriação). Durante a gestação, o cuidado com esse corpo gestante já se dá com vistas a outro ser que, ainda, não é propriamente outro. $\mathrm{O}$ momento seguinte, após o parto, apresenta o ápice do cuidado necessário para com o recém-nascido. Além dos cuidados mais elementares, a mãe torna-se responsável pela alimentação desse neonato através da amamentação, sem a qual não sobreviveria. Assim, há uma dependência que se segue de imediato para com a figura da mãe. Os outros hábitos que daí se instauram dão margem a naturalizar o cuidado como sendo feminino.
} 
autonomia elas fomentam ao nutrir sua individualidade particular, e homens cidadãos que se tornaram autônomos e pensadores independentes que exercem o julgamento político autônomo para o bem geral de todos, graças ao cuidado amoroso de suas mães. ${ }^{15}$

Young está dialogando com William Galston, que toma a independência como virtude. Segundo ele, há líderes e cidadãos, e somente os primeiros devem poder tomar decisões públicas. Já os cidadãos, não devem exigir mais do Estado do que podem contribuir através de taxas e impostos. Segundo análise de Young, cria-se, portanto, toda uma classe de pessoas que são consideradas menos cidadãs que outras. "Privilegiar normativamente a independência neste sentido, e faz̧er dela a virtude primária da cidadania, implica em julgar um número altíssimo de pessoas nas sociedades liberais como menos do que cidadãos completos." ${ }^{16}$. Para Young a independência (no sentido da autossuficiência) não deve ser uma virtude básica da cidadania. Para tanto, distingue os dois sentidos de independência (autossuficiência e autonomia) conforme explicitado acima, já que a autonomia deve ser um direito de todo indivíduo, o qual, por sua vez, deve ser considerado um cidadão mesmo que dependente economicamente. A noção moderna republicana de cidadania tende a amarrar esses dois sentidos: se o indivíduo não é um proprietário autossuficiente, então está subordinado a um proprietário para ter suas necessidades alcançadas e, logo, não pode ser um cidadão por completo. A extensão da cidadania para pessoas antes subordinadas significa quebrar essa ligação entre autonomia e autossuficiência. Trabalhadores e mulheres devem poder pensar por si mesmos, existindo políticas que garantam que possam tomar decisões sobre suas vidas e ações, sem depender do aval de seus empregadores e maridos, aos quais normalmente são dependentes economicamente. Esta autonomia comumente é dada apenas àqueles que são autossuficientes (logo, aqueles considerados cidadãos na lógica proposta por Galston).

Entramos assim no terreno da esfera pública em referência ao Estado. Quem pode ou não fazer política pública também se insere na lógica da divisão sexual do trabalho, pois aqueles considerados cidadãos, normalmente são homens. Mais, insere-se na lógica das hierarquias de poder baseadas no gênero, uma vez que há a pressuposição de que, para se ocupar um cargo público, as características desejáveis são aquelas ligadas ao masculino ${ }^{17}$. A esfera pública, desde a experiência da pólis grega — tida como experiência democrática paradigmática — até os dias atuais, é terreno ocupado majoritariamente por homens. De acordo com Young, embora diversas autoras ${ }^{18}$ abordem tal problemática, temas como a sexualidade e reprodução ficam de fora das discussões sobre gênero e justiça ${ }^{19}$.

Ora, se as mulheres ocupam a esfera privada, estando a esfera pública repleta de homens, as decisões tomadas neste âmbito vão certamente privilegiar as estruturas baseadas no gênero. Se as políticas públicas são pensadas e elaboradas por homens, a sexualidade e a

\footnotetext{
15 YOUNG, Intersecting Voices: Dilemmas of Gender, Political Philosophy, and Policy, p. 124

${ }^{16}$ YOUNG, Intersecting Voices: Dilemmas of Gender, Political Philosophy, and Policy, p. 125

17 A virtude da independência implica num senso de autonomia pessoal e autoconfiança, com habilidade para reflexão, sem estar propenso a impulsos imediatos ou cego por emoções (estes últimos ligados ao feminino). Tais características seriam aquelas desejáveis ao ser político pretensamente neutro que estaria apto a zelar pelo bem comum.

${ }^{18}$ Susan Okin, Hannah Arendt e Judith Butler são autoras importantes acerca da distinção entre o público e o privado, e em qual esfera estaria a ação política.

${ }^{19}$ Note-se que, para Young, correntemente o debate de gênero está atrelado ao ideário de justiça, o qual, por sua vez, não é dissociável do embate público vs. privado. Cf. YOUNG, Justice and the Politics of Difference.
} 
reprodução das mulheres ainda se encontram sob sua tutela. A ilegalidade de se realizar um aborto, presente ainda hoje na maioria dos países, torna evidente esta questão.

Young (capítulo IV de Vozes que se Cruzam) faz uma análise pungente sobre mulheres dependentes químicas que tornam-se ou são mães. Aportando a problemática no seio da crítica à política punitivista, baseada em Foucault e em suas noções de poder disciplinar e do discurso confessionário, Young argumenta que o tratamento dado às mulheres, nos casos por ela analisados, geralmente operam a fim de ajustarem-nas ao gênero, raça, e estrutura de classe dominantes, despolitizando e desindividualizando suas situações. Cumpre ressaltar que aqui também está pressuposto o valor da independência; isto significa que, se há dependência química, esta é de responsabilidade de quem escolheu este caminho ${ }^{20}$. Tal lógica é ainda mais perversa quando observada do ponto de vista de mulheres que, na maioria das vezes são mães solo, e devem se haver com a responsabilidade de cuidar de uma criança. O aborto relaciona-se a este tema, uma vez que da mesma maneira em que há a responsabilização desse indivíduo pela dependência química, há a responsabilização das mulheres que engravidam. Quando há a junção dos dois casos, o expoente da responsabilidade dispara e a mulher é vista como um monstro que não foi capaz de cuidar de seu próprio filho.

A maioria dos estados onde políticas punitivistas em relação a grávidas adictas foram seguidas, não processam pessoas pelo uso de drogas em si. Especialmente onde isto ocorre, mulheres estão essencialmente sendo punidas por levarem uma gravidez a termo. Tal punição deve pressupor que mulheres são responsáveis por estarem grávidas, mas há diversas condições sociais que limitam a escolha de uma mulher sobre estar ou não grávida. A nossa ainda é uma sociedade onde as mulheres geralmente não são realmente livres nas suas relações sexuais com homens. $O$ acesso à contracepção, além disso, não é fácil para muitas mulheres, especialmente mulheres pobres e jovens. E, é claro, mesmo quando elas o têm, a contracepção nem sempre funciona. Com a rápida queda de acesso ao aborto para todas as mulheres nos Estados Unidos, mas especialmente para mulheres jovens e pobres, menos e menos mulheres têm a escolha de levar uma gravidez a termo. ${ }^{21}$

Esta temática é sensível, pois aproxima uma série de problemas: a pressuposição da independência individual, a postura punitivista do Estado em relação a pessoas dependentes químicas, a falta de acesso à informação sobre métodos contraceptivos ou até mesmo a eles próprios, a responsabilização unilateral da mulher por uma gravidez, a falta de acesso ao aborto e a não existência de serviços sociais apropriados para o acolhimento desse tipo de situação.

No capítulo seguinte, Young tece algumas considerações sobre “A Família”. A autora verifica que o papel da Família, enquanto instituição cultural e social sedimentada, é a base da ordem, ligando-se ao casamento e às normas heterossexuais através de um princípio de moralidade generificado. Sempre que há a afirmação da família como um valor moral social,

\footnotetext{
${ }^{20}$ Não caberia aqui reconstruir todo o argumento da autora acerca da crítica às políticas punitivistas. Inserimos o tema apenas para adentrarmos à nossa problemática. Para maiores considerações sobre o assunto, cf. YOUNG, Intersecting Voices: Dilemmas of Gender, Political Philosophy, and Policy.

${ }^{21}$ YOUNG, Intersecting Voices: Dilemmas of Gender, Political Philosophy, and Policy, p. 79.
} 
afirma-se também a estrutura de um pai e uma mãe, com a hierarquia do primeiro em relação à mulher e aos filhos. A lógica da afirmação desse modelo de família também serve ao propósito de criticar unidades parentais fora da lógica binária, homem e mulher. Young passa grande parte deste e do próximo capítulo refutando teorias que colocariam o foco do problema da criação de jovens no fato de haver mães solo. Há autores que defendem a família nuclear por pensar que neste tipo de relação a educação seria melhor e constituiria melhores cidadãos. Neste mesmo sentido, a solução para a maternidade solo — vista aqui como uma patologia social entre outras, como a pobreza, o stress e a discriminação das mulheres seria mantê-las casadas ou arranjar um marido para elas. A maternidade solo seria, portanto, além de desprezível, um problema a ser resolvido. Obviamente há uma inversão do problema, o qual Young pacientemente refuta.

Vemos em estreita relação com a família a instituição do casamento, que regula a sexualidade, a procriação e a propriedade. A instituição do casamento ainda é o pilar do poder patriarcal. Gayle Rubin estuda As Estruturas Elementares do Parentesco de Levi-Strauss, e nos revela como as mulheres serviam como moeda de troca para se criarem laços entre diferentes grupos sociais. O casamento viria a este propósito, enquanto os filhos dariam vazão à transmissão da propriedade privada. Carole Pateman, por sua vez, nos revela como as práticas da prostituição, pornografia, estupro, assédio sexual fazem parte ou derivam do casamento. Mas o que devemos salientar neste debate, através dos escritos de Young, é como a instituição do casamento é fundamentalmente injusta e deveria ser eliminada, portanto. $O$ argumento não vai contra relacionamentos estáveis entre homens e mulheres, mas ataca principalmente a divisão sexual do trabalho dentro dele, a dependência e os valores que consigo traz. Young nos mostra como ainda há um senso de respeitabilidade e legitimidade ligados à instituição do casamento, tendo por consequência tornar desviante e mal visto aqueles que não se enquadram a esta norma, bem como observar facilidades quando seguida - como, por exemplo: planos de seguros, facilidade nos acessos à adoção, à propriedade privada, ao crédito, etc.

A proposta de Young é alargar o conceito de família e estender os direitos e deveres dos familiares para estas novas formas. De forma resumida, para a autora, a formação de uma família não precisa pressupor relações sexuais. Os benefícios do casamento deveriam ser oferecidos a todos que optem por formar uma família — família esta que não implica em procriação, nem em parentes consanguíneos. Mas, um dos problemas (e objetivos) centrais da família é justamente a procriação. Novamente, de modo simplificado, o argumento forte aqui é que se todos afirmam que as crianças são o futuro de uma nação, bem como entendem serem elas as futuras forças de mão de obra, seu cuidado deveria ser encarado por toda a sociedade. O Estado, inclusive, deveria ter um maior papel na educação de crianças; ou seja, não devemos assumir que apenas os pais são responsáveis por seus filhos. O Estado ${ }^{22}$, portanto, não é neutro em relação à criação das crianças e em relação às famílias (aqui já no novo sentido proposto), mas deve dar o suporte para que todas desenvolvam-se igualmente. Mais, uma sociedade justa deve prever o aborto e contracepção como um direito, garantindo e dando o suporte necessário, também, à gestação daquelas pessoas que assim optarem.

22 Para maiores reflexões sobre política em Young, cf. YOUNG, Inclusion and Democracy e YOUNG, Justice and the Politics of Difference. 


\section{Conclusão}

Isto posto, analisamos como as estruturas nos três níveis estão presentes em questões que de algum modo se conectam com a maternidade. A divisão sexual do trabalho evidencia que, de um lado, a esfera privada guarda o trabalho do cuidado, sempre invisibilizado e não remunerado, entretanto, essencial à esfera pública que, por sua vez, é excludente em diversos níveis. Desde que às mulheres foi-lhes negado o controle sobre seus corpos, acusadas de bruxaria, e a prática das parteiras e curandeiras passou ao domínio da medicina - aqui pensando especialmente na questão da maternidade - esses temas passaram, também, ao domínio masculino. Podemos observar que cada vez mais os controles dos corpos e do trabalho reprodutivo foi sendo expropriado e apropriado com fins específicos. Note-se que a maternidade sempre se apresenta como uma questão nos debates feministas, não ocupando, contudo, posição de centralidade. Penso, contudo, que esse seja o caso que mais nos revele sobre relações de opressão.

Todas as esferas que envolvem a questão da maternidade ocultam, de algum modo, relações opressivas. De saída, a educação sexual dada às mulheres e aos homens — quando dada - sustenta fundamentos machistas e patriarcais. À criança identificada como menina, desde cedo lhe é inculcada - como brincadeiras com bonecas, casinhas, etc. - a responsabilidade da procriação, como se fosse um destino imutável e inquestionável. Observe-se que as mulheres que optam conscientemente em não se tornarem mães - seja porque de fato assim o desejam, ou porque a sociedade ainda lhes relega a maior parte da responsabilidade e do cuidado com essa futura criança — ainda sofrem estigmas e encontram dificuldades frente à medicina para conseguir fazer isso em definitivo. $\mathrm{O}$ acesso aos métodos contraceptivos ainda não é amplamente disponível para todas as mulheres. O direito ao aborto ainda não é positivado em muitos países. Tudo isso nos indica que não há liberdade sobre seu próprio corpo.

Cada corpo é um corpo singular em situação, isto é um fato. Outro fato, porém, é que um corpo equipado com um útero e ovários ainda é o único capaz de realizar o trabalho reprodutivo. E isto foi apropriado de modo que: este seja um trabalho tanto invisível quanto mais necessário que as tarefas do cuidado - essas mesmas, como tentamos demonstrar, naturalizadas como consequência da maternidade. Mesmo quando pensamos na inserção no mercado de trabalho como forma de dar autonomia financeira às mulheres, estas acabam se sobrecarregando com triplas jornadas — o que já nos ensinavam as mulheres negras. E, mesmo que estas afirmem sua reprodução como modo de subverter a opressão de raça, verificamos que estas mesmas costumam estar mais propensas às opressões ligadas à maternidade. Isto porque, quanto mais excluídas e marginalizadas, mais estão sujeitas a relações de opressão. De modo que, enquanto houver uma sociedade pautada pelo gênero, haverá estruturas de constrangimento que não dão opções de fato à escolha livre da maternidade, em maior ou menor grau. Há neste cenário — quase sempre — ausência de opção. 


\section{Referências Bibliográficas}

BEAUVOIR, Simone de. O segundo sexo. Rio de Janeiro: Nova Fronteira, 2009.

BUTLER, Judith. Problemas de Gênero: Feminismo e Subversão da Identidade. Trad. de Renato Aguiar. Rio de Janeiro: Civilização Brasileira, 2018.

DAVIS, Angela. Mulheres, Raça e Classe. Trad. de Heci Regina Candiani. São Paulo: Boitempo, 2016.

FEDERICI, Silvia. Calibã e a Bruxa: Mulheres, Corpo e Acumulação Primitiva. Trad. coletivo Sycorax. São Paulo: Elefante, 2017.

hooks, b. "Mulheres negras: moldando a teoria feminista". In: Revista Brasileira de Ciência Politica, n. 16, pp. 193-210, 2015.

MISSAGGIA, Juliana. "Ética do cuidado: duas formulações e suas objeções". In: Blogs de Ciência da Universidade Estadual de Campinas: Mulheres na Filosofia, v. 6 n. 3, pp. 55-67, 2020.

MOI, Toril. What Is a Woman?: And Other Essays. New York: Oxford University Press, 1999.

OKIN, Susan Moller. "Gênero, o público e o privado". In: Estudos Feministas, v. 16, n. 2, pp. 305-332, 2008.

PATEMAN, Carole. O contrato sexual. Rio de Janeiro: Paz e Terra, 1993.

RUBIN, Gayle. Políticas do Sexo. Trad. de Jamille Pinheiro Dias. São Paulo: UBU, 2017.

YOUNG, Iris Marion. Inclusion and Democracy. New York: Oxford University Press, 2000. Intersecting Voices: Dilemmas of Gender, Political Philosophy, and Policy. Princeton, N.J.:

Princeton University Press, 1997. Justice and the Politics of Difference. Princeton: Princeton University Press, 1990.

On female body experience: "Throwing like a girl" and other essays. New York: Oxford University Press, 2005. 